\title{
The implementation of Alternative Learning System in public schools in Isabela, Philippines
}

\author{
Vernaliza S. Baccal ${ }^{1}$, Rashid Ceazar G. Ormilla ${ }^{2}$ \\ ${ }^{1}$ Faculty, Department of Education, Isabela, Philippines \\ ${ }^{2}$ Chairperson, BEEd Program, College of Education, Ifugao State University-Potia Campus, \\ Philippines \\ *e-mail: ormillarashidceazar@gmail.com
}

Received: 18 August 2020; Accepted: 17 December 2020; Published: 02 January 2021

To cite this article (APA): Baccal, V. S., \& Ormilla, R. C. G. (2021). The implementation of Alternative Learning System in public schools in Isabela, Philippines. EDUCATUM Journal of Social Sciences, 7(1), 19-29. https://doi.org/10.37134/ejoss.vol7.1.3.2021

To link to this article: https://doi.org/10.37134/ejoss.vol7.1.3.2021

\begin{abstract}
The main purpose of the Alternative Learning System (ALS) is to eradicate illiteracy among out of school children, youths and adults who are school dropouts and to those who are deprived of education in order to complete elementary and secondary education outside the formal school system. Thus, this study was designed to determine the level of implementation of the Alternative Learning System (ALS) in the Schools Division of Isabela. It utilized the descriptive-correlational method involving fourteen (14) districts. The main instrument for data collection is the survey questionnaire while weighted mean, Mann-Whitney U-test and Kruskal-Wallis Htest were carried out to answer the research objectives of the study. Results of the study showed that implementation of ALS program in public schools in the Division of Isabela are commendable. They perceived the implementation of ALS program generally as very good. The data showed that majority of them revealed that relevance of instructional materials use during ALS sessions was outstanding. They affirmed that facilities and equipment were always available, enough, relevant, with quality, accessible and safe in the learning centers. They also perceived that financial resources appropriation, availability, and sufficiency exist in the ALS program implementation. Moreover, majority of the respondents revealed that establishing linkages, participation of stakeholders such as parents and government officials and attitude of ALS implementers were very good. There are significant differences in some areas of the factors in the implementation of Alternative Learning System. On the basis of the results of the study, it is then recommended that ALS Implementers consistently build and maintain positive working relationship with the barangay officials and other stakeholders to win their full cooperation in the implementation of the ALS programs and projects. Furthermore, the learners are advised to be guided accordingly and comply with the regular attendance as scheduled by the assigned ALS implementer in the ALS centers, and other linkages and partners may work hand and hand to extend financial support as needed in the implementation of the ALS program. Nevertheless, there should be a proper monitoring and evaluation tool designed by the Department of Education (DepEd) to identify priorities and needs and ensure proper technical assistance to ALS implementers in the field. For further research, this study can be replicated in the higher level utilizing other parameters.
\end{abstract}

Keywords: implementation, alternative, learning system, implementer

\section{INTRODUCTION}

Education is given a very high regard in the Philippines. It receives the most of appropriations among the social service areas. The heavy debt service burden of the country, however, prevented the educational sector from receiving enough and necessary service to each clientele. In the Philippines and some other countries, the children who faced the most severe barriers to education, such as those associated with gender, poverty, displacement, disability and/or ethnicity are still left behind. Many of these children do not get the chance to go to school because their families bank on them for labor, the 
distance and the risk in going to school. Some cannot attend because the local schools lack water points, latrines or accessible facilities for children with disabilities.

The greatest challenges are met by children who encounter several of these barriers. Executive Order No. 356 entitled "Renaming the Bureau of Non-formal Education to Bureau of Alternative Learning System (BALS)" states that "it is the declared State policy to protect and promote the right of all citizens to quality basic education and shall take appropriate steps to make such education accessible to all and shall maintain and support a complete adequate, and integrated system of basic education relevant to the needs of the people and society. It shall establish and maintain a system of free and compulsory public education in the elementary level and free education in the high school level" (Sec. 2 of R.A. 9155, Governance of Basic Education Act of 2001). Each Filipino citizen young and adult has the privilege to undergo formal schooling. However, many Filipinos were being deprived of this right due to their destitute conditions and traditional cultures (Mendoza, 2011). The 1987 Philippine Constitution provides for the recognition and promotion of other forms of education other than formal education. Article XIV, Section 2, Paragraph (1) declares that the State shall establish, maintain and support a complete, adequate and integrated system of education relevant to the needs of the people and society and paragraph (4) concisely encourages non-formal, informal and indigenous learning systems as well as self-learning, independent and out-of-school study programs particularly those that respond to community needs. Equalizing opportunities in education is one of the most important conditions for overcoming social injustice and reducing social disparities in any country... and is also a condition for strengthening economic growth (UNESCO, 2008, p. 24).

In doing so, the Department of Education has designed a program called the Alternative Learning System(ALS) to address the issue and to comply with the UNESCO's Millennium Development Goal of eradicating illiteracy across nations and to provide all Filipinos the chance to have access to and complete basic education in a mode that fits their distinct situations and needs. This is a relative idea in the Philippine Educational System in order to prevent the increase of illiteracy in our country. The Alternative Learning System is a parallel learning system in the Philippines that provides a practical option to the existing formal instruction. When one does not have or cannot access formal education in schools, ALS is an alternate or substitute. ALS includes both the non-formal and informal sources of knowledge and skills (Section 12.1 Rules XII of R.A. 9155). However, the scenario is the basis of the conduct of this study. In view of this phenomenon, the researchers aimed to study the implementers and learners in the implementation of Alternative Learning System in the Schools Division of Isabela.

\section{LITERATURE REVIEW}

The Department of Education characterized Alternative Learning System (ALS) to cater out-of-school children, youth and adults who need basic and functional literacy skills, knowledge and values. These people are usually located in far-flung areas with no or limited access to formal schools. Specifically, this group of marginalized learners consists of street children, indigenous peoples, farmers, fisher folks, women, adolescents, solo parents, children in conflict areas not reached by the formal school system. In response to one of the challenges of the United Nations Educational, Scientific and Cultural Organization (UNESCO) on Millennium Development Goals (MDG) which is to achieve universal primary education, academe within the Philippines pose new challenges for the improvement of literacy rate among Filipinos. In fact, the current status in Philippine education as revealed by the Department of Education shows that only six out of ten students who entered Grade 1 are able to finish Grade 6, and out of these six (6) elementary graduates, only four (4) are able to finish 4th year high school.

According to Cagurangan, et al. (2017), learning strands are equivalent to subjects in the formal school system. Learning strands, topics or skills include communication skills in English and Filipino, scientific and critical thinking skills, mathematical and problem solving skills, life and career skills, understanding the self and society and digital citizenship. For ALS to be truly parallel with the formal education system, same standards and competencies are set for both in the K-12 Curriculum to achieve the goal of producing holistically developed Filipinos with $21^{\text {st }}$ century skills. However, learners' acquisition of $21^{\text {st }}$ century skills is low. This implies further that their local environment strongly affects the way they learn which includes the community support they are receiving such as the community 
learning centers. Moreover, teachers should teach the importance of content of a certain topic that is rooted in the cultural context or in a local setting and the information that students should acquire.

The community and schools must collaborate in achieving specific objectives, thus enriching not just their intellectual capacity but also their social awareness. Pappas (2013) asserted that in the instruction or in the method of teaching, Knowles' four principles of andragogy which is applied in adult learning are: (1) adults need to be involved in the planning and evaluation of their instruction; (2) experience (including mistakes) provides the basis for the learning activities; (3) adults are most interested in learning subjects that have immediate relevance and impact to their job or personal life, and (4) adult learning is problem-centered rather than content-centered. In addition, he underscored the life skills approach of ALS which is defined as the abilities for positive and adaptive behavior that enable individuals to deal effectively with the demands, challenges, experiences and situations of everyday life. It is the principal teaching-learning methodology of Alternative Learning System.

In addition, Apao, et al. (2014) stated that the Alternative Learning System A\&E program was effective in cultivating the life skills of the recipients. The program improved the quality of living of the respondents as they continue their pursuit for meaning and significance in life. It proved that students still learn and acquire the life-long competencies even outside the walls of the formal school system. It was an option for those who wanted to improve their quality of living and rise beyond poverty. As an alternative to the formal school system, the government needs to provide the physical and financial resources for sustainability of the ALS program. Its governance should be strengthened to maximize the participation of stakeholders to bring the out-of-school adults to school and let them finish their studies, thereby increasing literacy. The strong support and collaboration of the stakeholders, the commitment of both learners and mobile teachers are necessary in the effective implementation of the program.

The Kolb's Experiential Learning focuses on learners reflecting on their experience of doing something, so as to gain conceptual insight as well as practical expertise. Kolb's Experiential Learning Model suggests four stages in this process: active experimentation, concrete experience, reflective observation and abstract conceptualization (William, 2015).

Similarly, Schiro (2012) pointed out that experience and education of Dewey proves that children need assistance from teachers in developing a concrete understanding of the world. In order to effectively assist students, teachers must first observe children and from those observations determine the types of experiences they maintain and have an interest in. For Dewey, the path to quality education requires learning that is built on previous knowledge and experiences, presented in a highly structured and well planned manner.

Cagurangan, et al. (2017) claim that ALS implementers should adopt localized instructional materials to suit to the localized setting of the learners. Meanwhile, most of the skills are low such as the creativity skills and the innovation skills.

Moralista and Delarierte (2014) also stressed that an explanation for the diverse status and learning styles of the learners are the increasing learning competencies which are the major problems encountered by the implementers as there are advance and slow learners affecting how the interference or cognition abilities to task-related factors such as the complexity of a task or lesson.

In addition, the instructional managers should look into the factors contributing to the learning motivation of the ALS learners in involving themselves in school or any instructional program. Alternative Learning System providers should also revisit and review the programs and balance out the relationship of the learner's ability and appropriateness, complexity and demands of the tasks given to them as the relationship of these factors are crucial in bridging the willingness of the learners needed for a successful achievement outcome (Atilano, et al., 2016).

The Alternative Learning System only requires students to choose schedules according to their choice and availability. The program has two different schematics for conducting instruction: school-based and community- based. On the school-based program, instructions are conducted in school campuses while in the community-based program, formal instruction is conducted in community halls or on private places. The ALS program follows uniform lesson modules for all academic subjects covering the sciences, mathematics, English, Filipino, social studies, current events among others. Delivery of instruction is provided by government-paid instructors or by private non-government organization. Aside from schematics, the program has two levels: elementary and secondary. Students have to start from elementary level, then proceed to high school level. If a student is a graduate of elementary under 
a formal classroom system, the student is automatically admitted to the secondary levels depending on which year level the student stopped schooling. Program administration is held by the Department of Education, an agency of the government of the Philippines in-charge in providing education to all Filipinos. Private non-government organizations may deliver the program but still under the supervision of the Philippine education agency. After finishing the curriculum, all participants of the program belonging to a particular education district are given the final comprehensive examinations covering all subject areas in the curriculum. Successful examinees are then grouped together in a closing ceremony where they are given their certificate of completion either for the elementary or secondary level. McDonald also stressed that in the elementary level, if a student has never reached the first grade, the student will be admitted in the Grade 1 level with the corresponding module of instruction given. The students have to finish all the modules for the first grade level and pass assessment test before proceeding to the next level. After successfully finishing all the modules, the students are given the comprehensive examinations prior to admission in the graduation (McDonald, 2012).

According to McDonald (2012), the Alternative Learning System evolved from the non-formal education that has been conducted by the government of the Philippines. Previously, non-formal education was mostly concentrated in instruction in livelihood skills training with basic readiness to attend classroom instructions on a daily basis just like the formal education system. Secondary education has now become a prerequisite in vocational technology and college education in the Philippines. Livelihood trainings however, do not need formal or non-formal education in the Philippines. Moreover, instructional materials are highly important for teaching, especially for inexperienced teachers. Teachers rely on instructional materials in every aspect of teaching. They need materials for background information on the subject they are teaching. Young teachers usually have not built up their expertise whenever they enter into the field. Teachers often use instructional materials for lesson planning. These materials are also needed by teachers to assess the knowledge of their students. Teachers often assess students by assigning tasks, creating projects, and administering exams. Instructional materials are essential for all of these activities. Teachers are often expected to create their own lesson plans. This can be difficult, especially if the teacher has limited background knowledge on the subject. Teachers are expected to have a wide variety of expertise in many different fields. Often, they need instructional aides to supplement their knowledge. Instructional materials can help provide background knowledge on the subject the teacher is planning for, and offer suggestions for lesson plans. Lesson planning is often the most stressful aspect of teaching. Teachers are usually dependent on them to do their job properly.

Stakeholders offer important insight into each phase of program planning, implementation and evaluation in the Alternative Learning System. Stakeholders are most commonly involved at the beginning stages of program planning. They are able to provide insight for the various needs that a program or curriculum should meet. Experience shows that once the goals have been set in the first part of program development, stakeholders are sometimes not consulted in latter stages of program implementation and evaluation. This is unfortunate because stakeholders have the potential to illuminate issues and needs during the course of program implementation (Banach \& Gregory, 2001). According to Abasolo (2017), the accomplishment of ALS implementation will depend on the ability to bring partnership to the local level, to the provinces, to the cities, to the municipalities, and the barangays. Cultivation and coordination of partnerships with the private sector, international agencies, national government agencies, LGUs, and other community-based groups involved in mobilizing donations must be done to ensure that these are reliable and associated with the goals of the DepEd.

In addition, he also pointed out that facilities and equipment can have a deep influence on both teacher and student outcomes and can affect health, behavior, engagement, learning, and growth in achievement. The findings show that the implementers know that the learning center climate is one of the most treasured assets to the teaching-learning situation and they work hard to maintain a healthy climate and a learner friendly environment in the learning center. Most of the learners are satisfied with facilities and equipment which are being used by the implementers in the implementation of the program. There are learning centers in the community on which the facilities are not always available just because they are conducting there the sessions on the learners' residence or any vacant and available lot to conduct ALS learning sessions. It was really proven that physical facilities and equipment can have a deep influence on both teacher and student outcomes and can affect health, behavior, engagement, learning, and growth in achievement. 
Realistic learning approach in the lessons must be provided to relate lessons to real life positions. Tools and techniques using the multi-media that will enhance resourcefulness and innovativeness are to be provided. To improve teaching performance, a training seminar concerning managing difficult learners and implementing the program at the division level must be conducted and stakeholders must request for funding in implementing the ALS program and intensifying campaign/lobby for legislators to take in budget for ALS. As for the learners' performance, immersions are recommended for exposures, sessions to address the weakness on limited awareness to the different cultures together with their teachers (Abasolo, 2017).

Finally, he emphasized that the implementers can fully implement the program if the barangay officials cooperate and are fully aware of the ALS program so that there is no problem when it reaches the community. Community involvement is one of the major objectives of the planning, implementation and monitoring of ALS program. Several NGOs and LGUs have also played active roles in activities relating to strengthening and community awareness activities for the out-of-school youth and adult as Madrid (2004) emphasized that teachers' competency in teaching is a significant factor for the development of the learner.

\section{CONCEPTUAL FRAMEWORK}

The framework shows that Alternative Learning System (ALS) is a program designed to provide a practical option to the existing formal instruction. When one does not have or cannot access formal education in schools, ALS is an alternate or substitute. ALS includes both the non-formal and informal sources of knowledge and skills. Education in the Philippines poses new challenges in the academe for the improvement of literacy rate among Filipinos in response to one of the challenges of the United Nations Educational, Scientific and Cultural Organization (UNESCO) on Millennium Development Goals (MDG) which is to achieve universal primary education. Many Filipinos do not have a chance to attend and finish formal basic education due to many reasons. Some drop-out from schools while some do not have schools in their communities. Since every Filipino has a right to free basic education, the government established ALS to provide all Filipinos the chance to have access to and complete basic education in a mode that fits their district situations and needs. The concept behind this study is inspired through the Input-Process-Output analysis. The first stage focuses on the input. The input concentrated to the level of alternative learning system concerning both the implementers and the ALS learners. Furthermore, the components of the paradigm of the study will also focus on the process which indulges in determining the level of implementation of the alternative learning system through administering a survey questionnaire. The last component of the paradigm stresses on the improvement and efficiency in the implementation of alternative learning system which the implementers and the learners participated in.

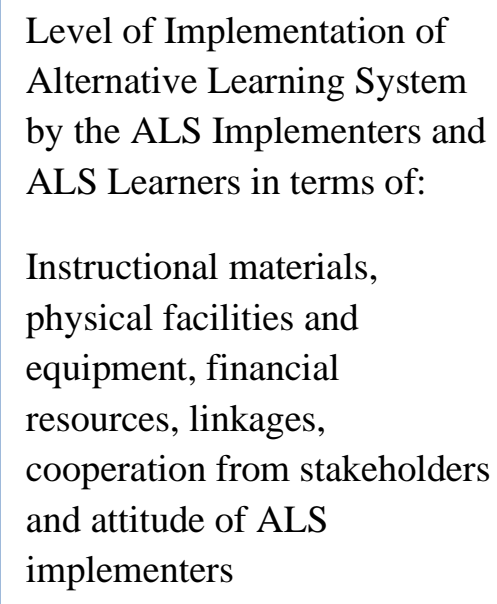

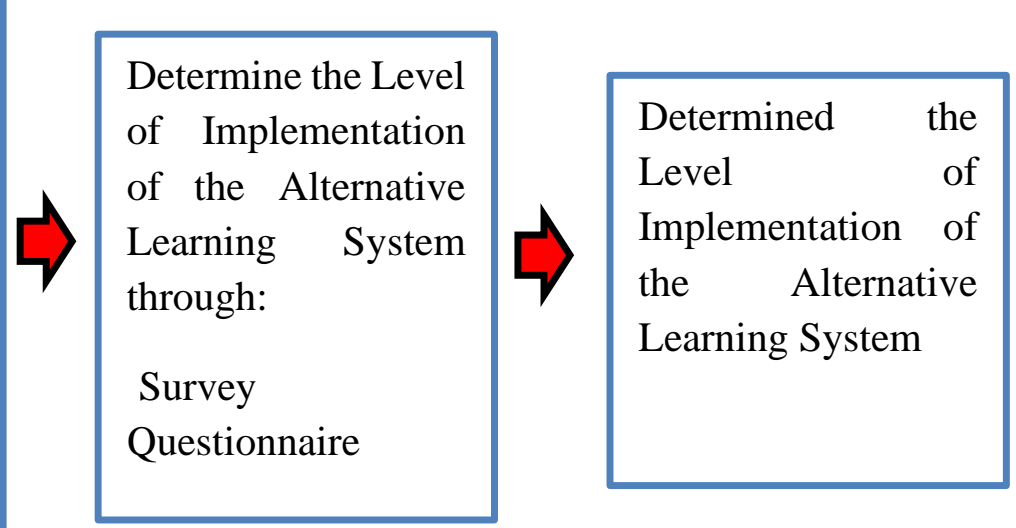




\section{RESEARCH OBJECTIVES}

This study was designed to determine the level of implementation of the Alternative Learning System (ALS) programs in the Schools Division of Isabela. Specifically, it aimed to: (1) Determine the level of ALS implementation as perceived by the implementers and learners in terms of instructional materials, physical facilities and equipment, financial resources, linkages, cooperation from stakeholders and attitude of ALS implementers; and (2) Analyze the difference in the perception of implementers and learners on the level of implementation of the ALS in the Schools Division of Isabela.

\section{METHODOLOGY}

The study used the descriptive-correlational method to obtain relevant information regarding the level of implementation of Alternative Learning System. The descriptive method of research is a fact-finding study with accurate and adequate interpretation of the findings. The respondents who participated were the District ALS implementers and ALS learners in the Schools Division of Isabela. The sample of implementers and learners were determined at $95 \%$ level of confidence at 5\% margin of error and proportionally allocated per respondent district. There were 402 respondents randomly selected from 44 districts in the Schools Division of Isabela. Of this number, 72 or 17.91 percent comprised the implementers and 330 or 82.09 percent were learners. The primary data were collected using a structured questionnaire on ALS Implementation developed and validated by the researchers and expert teachers. The instrument used a five-point Likert scale with 5 as the highest and 1 as the lowest. The data collected were coded and interpreted as follows: (5) 4.50-5.00 - Outstanding, (4) 3.50-4.49 - Very Good, (3) 2.50-3.49-Good, (2) 1.50-2.49 - Fair, (1) 1.00-1.49 - Poor. The researchers secured a written permit from the Schools Division Superintendent in the Schools Division of Isabela. After the permission was given, the researchers explained the purpose of the study to the selected respondents in order to extract the needed and reliable information. Finally, at the end of the survey period, all data were collected. The data gathered were classified, tallied, tabulated and subjected to statistical tools and analyses utilizing descriptive statistics such as mean to elaborate the data gathered in the rational and operational aspects of the implementation of Alternative Learning System. Mann-Whitney U Test and Kruskal-Wallis H-test were used to answer differences of perception of respondents.

\section{FINDINGS AND DISCUSSION}

\section{Implementation of Alternative Learning System}

\begin{tabular}{l} 
Table 1. Perceived Level of Implementation of Alternative Learning System in the Schools \\
Division of Isabela \\
FACTORS \\
\hline \hline
\end{tabular}


The perceived level of implementation of ALS in terms of instructional materials, facilities and equipment and financial resources is shown in table 1 . It can be noticed that almost all the items from the three factors were interpreted as very good except for item 3 under instructional materials, "Quality instructional materials are available during ALS sessions" was interpreted as outstanding and obtained the highest mean of 4.50. This strengthened by Woolfolk's (2007) that instructional materials are effective in delivering quality education and are also used for motivating learners. Likewise, in terms of facilities and equipment, item 3, "Relevance of ALS learning centers to the instructional materials got the highest mean of 4.46 while "Facilities and equipment for ALS are always available" got the lowest mean of 4.16 but both descriptively interpreted as very good. Abasalo (2017) pointed out that physical facilities and equipment has proven to have a deep influence on both teacher and learner outcomes and can affect health, behavior, engagement, learning, and growth in achievement. Moreover, in terms of financial resources, it is revealed that the highest mean rating of 4.38 pertains to the "Availability of funds for ALS special programs" and item 3 "Appropriation of ALS programs and projects" obtained the lowest mean of 4.22 however both descriptively interpreted as very good. The findings of the study implicates that the implementation of ALS program among implementers and learners were very good and in one point outstanding. The results further ensure that there were adequate provisions, available, appropriate and relevant instructional materials, facilities and equipment, and financial resources in the implementation of the programs of ALS.

Table 2. Perceived Level of Implementation of Alternative Learning System in the Schools Division of Isabela

FACTORS Mean Desc

\begin{tabular}{lcc}
\hline LINKAGES & & \\
1.Sourcing out initiatives for prospective linkages and partners. & 4.03 & VG \\
2. Establishing a good relationship with partners. & 4.19 & VG \\
3.Inclusion of partners and other linkages to ALS programs and projects. & 4.01 & VG \\
4.Intensifying strategies to gain many linkages inside and outside the & & \\
$\quad$ community. & 3.67 & VG \\
5.Implementing a plan of action for linkages and partners to see outcomes. & 3.81 & VG \\
COOPERATION FROM STAKEHOLDERS & & \\
1.Attendance in Meetings and Planning Sessions & 4.49 & VG \\
2.Attendance and participation in ALS activities & 4.35 & VG \\
3.Involvement of Parents, Teachers and government officials & 4.32 & VG \\
4.Moral support in ALS activities & 4.15 & VG \\
5.Provision of Constructive Feedback & 4.17 & VG \\
ATTITUDE OF ALS IMPLEMENTERS & & \\
1.Dedication and Passion & 3.98 & VG \\
2.Leadership potentials & 3.80 & VG \\
3.Knowledge of ALS curriculum & 4.18 & VG \\
4.Teaching-Learning management & 3.78 & VG \\
5.Relationship with both internal and external stakeholders & 3.80 & VG \\
\hline \hline VG-very good & &
\end{tabular}

As reflected in Table 2, the respondents perceived the level of implementation of ALS as very good in terms of linkages, cooperation of stakeholders and attitude of ALS implementers. Moreover, each items of the three factors were evaluated as very good. This shows that ALS implementers and ALS learners recognized the importance of establishing partners/linkages, involvement of stakeholders and portraying right attitude of implementers in the implementation of programs and projects of alternative learning system. Specifically, in terms of linkages, "Establishing a good relationship with partners" on item 2 obtained the highest mean ratings of 4.19 and item 4 "Intensifying strategies to gain many 
linkages inside and outside the community" obtained the lowest mean of 3.67 and both descriptively interpreted very good.

Likewise, in terms of cooperation from stakeholders, item 1 "Attendance in meetings and planning sessions" got the highest mean of 4.49 and item 4 "Moral support in ALS activities" got the lowest mean of 4.15 and both rated as very good. According to Apao, Dayagbil, and Abao (2014) the strong support and collaboration of stakeholders and the commitment of both learners and ALS implementers are necessary in the effective implementation of the program.

Consequently, in terms of the attitude of ALS implementers, most of them confirmed item 3, "Knowledge of ALS curriculum" with the highest mean of 4.18 and item 4 "Teaching-learning management" the lowest mean of 3.78 both interpreted equivalent to very good.

\section{Differences in the Respondents' Perception on the Level of Implementation of Alternative Learning System (ALS) in the Schools Division of Isabela}

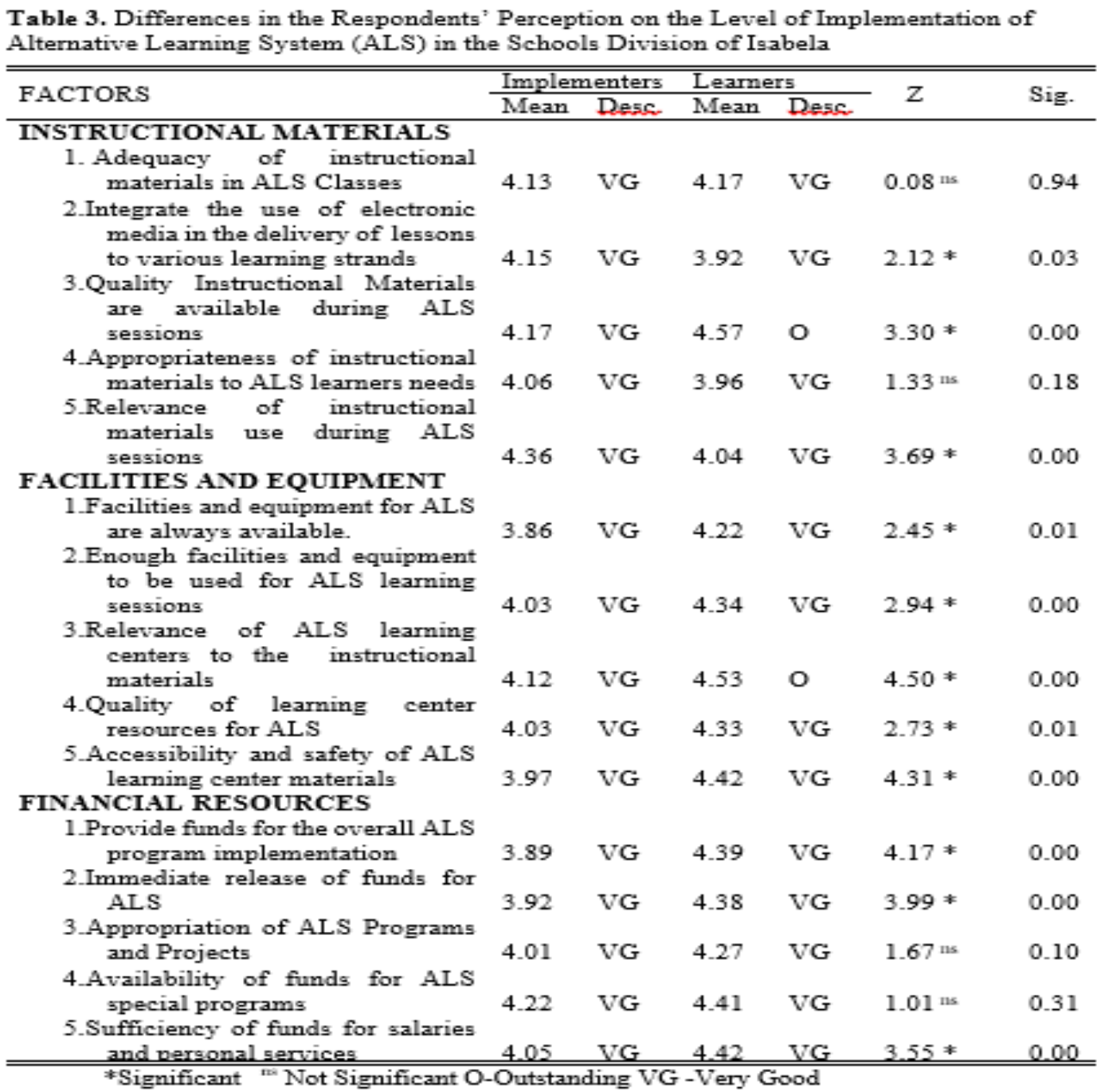

Table 3 presents the difference between ALS implementers and learners' perception on the level of implementation of ALS in terms of instructional materials, facilities and equipment and financial resources. Results indicate for instructional materials that item 2, "Integrate the use of electronic media in the delivery of lessons to various learning strands"; item 3, "Quality instructional materials are available during ALS sessions"; and item 5, "Relevance of instructional materials use during ALS sessions" were perceived to be significantly different between ALS implementers' and learners' as indicated by the $\mathrm{Z}$ values of 2.12, 3.30 and 3.69 respectively with a significance levels of less than 0.05 . Additionally, the mean ratings of 4.15 and 4.36 for items 2 and 5 given by the ALS implementers' are statistically higher than the mean ratings of 3.92 and 4.04 respectively from the learners'. This revealed 
that ALS implementers had significantly a better perception than learners in which instructional materials were adequately prepared and ensures relevance during ALS classes by the implementers. However, the mean rating of 4.57 given by the learners for item 3 and a mean rating of 4.17 from the implementers indicates that learners' perception is statistically higher than implementers' perception. This indicated that learners had a significantly better perception than implementers.

On the other hand, in terms of facilities and equipment, all items from 1 to 5 were perceived to be significantly different between the two respondents having a $\mathrm{Z}$ values ranging from 2.45 to 4.50 and with a significance levels of less than 0.05 . Thus, the higher mean ratings from 4.22 to 4.53 from the learners' perception were statistically higher than the mean ratings from 3.86 to 4.12 from the implementers' perception, respectively. This result further indicates that learners had a significantly better perception than the implementers as to the availability, accessibility and safety of facilities and equipment used in ALS.

Moreover, in terms of financial resources, the mean ratings from 3.89 to 4.22 from the implementers' perception and the mean ratings from 4.27 to 4.42 from the learners' perception were very good. Accordingly, they affirmed that they have very good provision of funds for the overall ALS program implementation, appropriation and releasing of funds to programs and projects, availability and sufficiency of funds for salaries and personal services.

Thus, the $\mathrm{Z}$ values of $3.55,3.99$ and 4.17 with significance levels of less than 0.05 are significant in three of the items. Thus, the higher mean ratings from 4.38 to 4.42 from the learners' perception were statistically higher than the mean ratings from 3.89 to 4.05 from the implementers' perception, respectively. This result further indicates that learners had a significantly better perception than the implementers as to the immediate provision, appropriation, availability and sufficiency of funds for the financial resources in teaching in ALS.

\begin{tabular}{|c|c|c|c|c|c|c|}
\hline \multirow{2}{*}{ FACTORS } & \multicolumn{2}{|c|}{ Implementers } & \multicolumn{2}{|c|}{ Learners } & \multirow[b]{2}{*}{$z$} & \multirow[b]{2}{*}{ Sig. } \\
\hline & Mean & Desc & Mean & Desc & & \\
\hline \multicolumn{7}{|l|}{ LINKAGES } \\
\hline 1.Sourcing out initiatives & & & & & & \\
\hline $\begin{array}{l}\text { prospective linkages and } \\
\text { partmers. }\end{array}$ & 3.35 & G & 4.18 & VG & $5.63 *$ & 0.00 \\
\hline $\begin{array}{l}\text { with partmers. } \\
\text { 3.Inclusion of partners and other }\end{array}$ & 4.23 & VG & 4.18 & VG & $1.03 \mathrm{~ns}$ & 0.30 \\
\hline $\begin{array}{l}\text { linkages to ALS programs and } \\
\text { projects. } \\
\text { 4-Intensifying strategies to gain }\end{array}$ & 4_00 & VG & 4.01 & VG & 0.14 ns & 0.89 \\
\hline $\begin{array}{l}\text { many linkages inside and } \\
\text { outside the community. } \\
\text { 5.Implementing a plan of action for }\end{array}$ & 3.73 & VG & 3.65 & VG & $1.00 \mathrm{~ns}$ & 0.32 \\
\hline $\begin{array}{l}\text { linkages and partmers to see } \\
\text { outcomes. } \\
\text { COOPERATION FROM }\end{array}$ & $4 \_23$ & VG & 3.72 & VG & $3.86 *$ & 0.00 \\
\hline STAKEHOLDERS & & & & & & \\
\hline $\begin{array}{l}\text { 1. Attendance in Meetings and } \\
\text { Planning Sessions }\end{array}$ & 3.95 & VG & 4.61 & $\mathbf{O}$ & $6.68 *$ & 0.00 \\
\hline $\begin{array}{l}\text { 2. Attendance and participation in } \\
\text { ALS activities }\end{array}$ & 3.88 & VG & 4.45 & VG & $4.56 *$ & 0.00 \\
\hline $\begin{array}{l}\text { 3. Involvement of Parents, Teachers } \\
\text { and government officials }\end{array}$ & 3.72 & $\mathrm{VG}$ & 4.45 & $\mathrm{VG}$ & $5.87 *$ & 0.00 \\
\hline 4. Moral support in AIS activities & 4.28 & $\mathrm{VG}$ & 4.13 & VG & $1.72^{\mathrm{mi}}$ & 0.09 \\
\hline $\begin{array}{l}\text { 5.Provision } \text { Feedback of Constructive } \\
\text { ATTITUDE OF ALS } \\
\text { IMPLENIENTERS }\end{array}$ & 4.01 & VG & 4.20 & VG & $1.92^{\mathrm{m}}$ & 0.06 \\
\hline 1. Dedication and Passion & 3.92 & VG & 3.99 & VG & $0.59^{m=}$ & 0.55 \\
\hline 2. Leadership potentials & 3.85 & VG & 3.79 & $\mathrm{VG}$ & $0.61=$ & 0.54 \\
\hline 3.Knowledge of AIS curriculum & 3.88 & $\mathrm{VG}$ & 4.25 & VG & $3.77 *$ & 0.00 \\
\hline 4. Teaching-L earning management & 3.99 & VG & 3.74 & VG & $2.03 *$ & 0.04 \\
\hline $\begin{array}{l}\text { S. Relationship with both internal and } \\
\text { external stakeholders }\end{array}$ & 3.94 & VG & 3.77 & VG & $1.02 \mathrm{~m}$ & 0.31 \\
\hline
\end{tabular}

As revealed on Table 4, the difference between the respondents' perception on the level of implementation of ALS in terms linkages, cooperation from stakeholders and attitude of ALS implementers indicates that in terms of linkages, item 1, "Sourcing out initiatives for prospective linkages and partners" and item 5, "Implementing a plan of action for linkages and partners to see outcomes" were perceived significant among the two respondents. However, the mean rating of 4.18 from the learners and 3.35 from the ALS implementers for item 1 indicates that learners had a better perception than ALS implementers while the mean rating of 4.23 from the ALS implementers and 3.72 for item 5 indicates also that ALS implementers had a better perception than learners. This shows that learners somehow look for prospective linkages and partners while ALS implementers implement a 
plan of action for linkages. The strong support and collaboration of the stakeholders, the commitment of both learners and ALS teachers are necessary in the effective implementation of the program (Apao, et al. 2014). Moreover, in terms of the cooperation from the stakeholders, items 1, "Attendance in Meetings and Planning Sessions", item 2, "Attendance and participation in ALS activities" and item 3, "Involvement of Parents, Teachers and government officials" were perceived to be significantly different of the respondents. The $\mathrm{Z}$ values of 4.56, 5.87 and 6.68 with significance levels of less than 0.05 are significant in three of the indicators. Thus, the higher mean ratings from 4.45 to 4.61 from the learners' perception were statistically higher than the mean ratings from 3.72 to 3.95 from the implementers' perception, respectively.

In terms of attitude of ALS implementers, item 3 on "Knowledge of ALS curriculum" and item 4 "Teaching-learning management" were perceived to be significantly different among the respondents as indicated by the $\mathrm{Z}$ values of 3.77 and 2.03 with a significance levels of less than 0.05 . However, the higher mean rating of 4.25 from the learners and 3.88 from the ALS implementers for item 3 shows that learners had a significantly better perception than ALS implementers, while, the ALS implementers had a better perception for item 4 than learners.

\section{CONCLUSIONS AND RECOMMENDATIONS}

The ALS program is an effective venue to lessen the out of school youths and adults as well as effective means to address unemployment issues in the country. The implementation of ALS program in Schools Division of Isabela are commendable although there are some areas that need enhancement like there were no permanent learning centers for the implementers and they need to move from one place to another where the numbers of out-of-school youth and adult in the community are located but there are also school heads who provided classroom to implementers for their sessions inside the school vicinity. Moreover, issues such as lack of actual application for the learners was noted. The support from the parents and government officials or the cooperation from stakeholders plays a big role in the ALS program for the security of the learners and implementers in the community. Implementers plays a vital role in the implementation of ALS program in the community, the attitude of being humble, patient and flexible must possessed by the Mobile Teachers in order to manage the different attitudes of their learners.

It was noted that both implementers and the learners were aware of the importance of the ALS program. In their perception, the implementation of ALS in the Schools Division of Isabela was generally very good. Majority of them revealed that relevance of instructional materials use during ALS sessions was outstanding. They affirmed that facilities and equipment were always available, enough, relevant, with quality, accessible and safe in the learning centers. They also perceived that financial resources appropriation, availability, and sufficiency exist in the ALS program implementation. Majority also of the respondents revealed that establishing linkages, participation of stakeholders such as parents and government officials and attitude of ALS implementers were very good. However, there are significant differences in some areas of the factors in the implementation of Alternative Learning System.

On the basis of the results of the study, it is recommended that ALS Implementers consistently build and maintain positive working relationship with the barangay officials and other stakeholders to win their full cooperation in the implementation of the ALS programs and projects. Further, the learners are advised to be guided accordingly and comply with the regular attendance as scheduled by the assigned ALS implementer in the ALS centers and other linkages and partners may work hand and hand to extend financial support as needed in the implementation of the ALS program. Nevertheless, there should be a proper monitoring and evaluation tool designed by the Department of Education (DepEd) to identify priorities and needs and ensure proper technical assistance to ALS implementers in the field. For further research, it is recommended that this study be replicated in the higher level utilizing other parameters. 


\section{REFERENCES}

Abasolo, A. (2017). "Developing a scheme of action for enhanced alternative Learning System". https://www.academia.edu/35207632/DEVELOPING A SCHEME_OF ACTION_FOR_ENHANCE D ALTERNATIVE_LEARNING_SYSTEM

Alternative Learning System, Department of Education (Deped Official Website. Retrieved from: http://deped.gov.ph/als

Apao, L., Dayagbil, F., and Abao, E. (2014). Alternative Learning System Accreditation and Equivalency (ALS A\&E) Program: Quality of life beyond poverty. International Journal of Interdisciplinary Research and Innovations 2(4), 20-26. Retrieved from www.researchjournals.com

Atilano, EB., Omanito RG., Zayra, CD., Domingo, JM., Garbin, SN (2016). Factors influencing the dropout rate in Alternative Learning System - Accreditation and Equivalency. The Online Journal of New Horizons in Education 6(4)

Banach, M. Gregory, PJ. (2001). Essential tasks, skills, and decisions for developing sustainable communitybased programs for children, youth, and families at risk. Journal of Extension, joe.orgExecutive Order No. 356, s. 2004 Renaming the Bureau of Non- Formal Education to Bureau of Alternative Learning System. Malacañang, Manila. https://www.officialgazette.gov.ph/2004/09/13/executive-order-no-356-s$2004 /$

Madrid, EP (2004). Commitment, instructional competence and teaching satisfaction of the Alternative Learning System instructional managers in the Division of Pasay, Unpublished Thesis, Faculty of the Graduate School, Laguna Northwestern College, San Pablo, Laguna, Philippines

Marquez, J. (2012). Project: Sagip-Dunong ALS Program (2002). Arnold Janssen Foundation Journal. https://www.academia.edu/36361852/TEACHERS_COMPETENCE_AND_LEARNERS_PERFORM ANCE_IN_THE_ALTERNATIVE_LEARNING_SYSTEM_TOWARDS_AN_ENRICHED_INSTRU CTIONAL_PROGRAM

McDonald, E. (2012). Setting Expectations. http://www.inspiringteachers.com/classroommanagement Discipline/setting_expectations.html, retrieved January 16, 2017

Mendoza, A. (2011). ALS in the Philippines as compared to other Asian countries.

Moralista, R. B., Delarierte, G. C. (2014). Alternative learning system (ALS education): Its influence on the intellectual abilities of the indigenous people. Asia Pacific Journal of Education, 1, 7-10.

Pappas, C. (2013). The Adult Learning Theory - Andragogy - of Malcolm Knowles https://elearningindustry.com/the-adult-learning-theory-andragogy-of-malcolm-knowles

Republic Act No. 9155 of Section 2 otherwise known as Governance of Basic Education Act of 2001. https:// www.officialgazette.gov.ph/2001/08/11/republic-act-no-9155

Schiro, M. S. (2012). Curriculum theory: Conflicting visions and enduring concerns. (2nd Ed.). Los Angeles: Sage Publications.

The Philippine Constitution (1987) of Article XIV, Section 2. https://www.officialgazette.gov.ph/constitutions/the-1987-constitution-of-the-republic-of-the philippines/the-1987-constitution-of-the-republic-of-the-philippines-article-xiv/

Tindowen DJC, Bassig JM, Cagurangan J-A. (2017). Twenty first century skills of Alternative Learning System Learners. SAGE Open. doi:10.1177/2158244017726116

United nations $\quad$ International Children's $\quad$ Emergency Fund (2008). http://www.ibe.unesco.org/fileadmin/user_upload/Policy_Dialogue/48th_ICE/General_Presentation$\underline{48 \text { CIE-English.pdf }}$

Woolfolk, Anita, 2007. Educational psychology. Boston: Pearson / Allyn and Bacon. 